\title{
AIDS, Social Sciences, and Health Education: A Personal Perspective
}

\author{
June E. Osborn, MD
}

\section{INTRODUCTION}

In 1981, on either coast of the United States, astute physicians first saw and reported a new disease syndrome. At first it occurred exclusively in a group of gay men who had a great many sexual partners, a group which was already known to be at risk for a multiplicity of microbial diseases which were rare in the general population. It took the form of exotic pneumonias or sarcomatous lesions which had previously been seen only in severely immunosuppressed individuals; and indeed these gay men were soon shown to be profoundly immunosuppressed themselves, but for no apparent reason. Once their infections or tumors became overt, they progressed rapidly and disastrously, with recurrent infections, neurologic symptoms and unrelenting wasting, diarrhea, and debilitation en route to their demise; and the average time from first diagnosis to death was often less than one year, even though the disease was seen largely in men in their $30^{\circ}$ s and $40^{\prime}$ 's. ${ }^{1}$

These first reports were followed inexorably by more such cases, and by addition of other so-called high risk groups. Intravenous drug abusers were afflicted, raising early in the epidemic the alarm that this might be a new blood-transmitted infection. Haitian immigrants to the United States were also at risk, for reasons which still remain unexplained. In due course. other groups such as hemophiliacs and infants of infected, addicted mothers were noted: and finally the addition of individuals to the list whose only "risk factor" was blood transfusion sounded a loud alarm, since the magnitude of the U.S. blood supply numbered millions of donors and recipients. Even in those early times (which, it should be noted, was only five years ago), the pivotal role to be played by social factors in handling the epidemic became evident; the fact that over $90 \%$ of those involved in the epidemic were in socially outcast groups-i.e., gay men and i.v. drug abusers - led to a great concern among the afflicted that the epidemic burgeoning among them was being ignored by the governmental establishment. It is difficult to assess the validity of that claim, except to note that less than five years later, biomedical science has made dramatic inroads on the problem, and that the areas of our ignorance that are going to do us harm are in the behavioral and social sciences. not in biomedical science.

June E. Osborn, MD is Dean of the School of Public Health and Professor of Epidemiology and of Pediatrics and Communicable Diseases at the University of Michigan, Ann Arbor, Michigan.

Address reprint requests to June E. Osborn, MD, University of Michigan School of Public Health, 109 S. Observatory Street, Ann Arbor, Michigan 481 09-2029. 
My own involvement with the AIDS epidemic began in early 1983 as it became increasingly evident that the nation's blood supply might be in jeopardy. I was a virologist-adviser to the U.S. Food and Drug Administration for a number of years, and the FDA officials asked me to serve as a consultant to their Blood and Blood Products Advisory Panel with respect to issues raised by the AIDS epidemic. Following their lead. in January of 1984 I was asked by the National Institutes of Health (NIH) to serve as chairman of an ad hoc committee on AIDS and the Nation's Blood Supply, advisory to the National Heart, Lung and Blood Institute. That committee had been formed at the request of the Assistant Secretary for Health in order to have ready a group of non-governmental experts who could give independent comment as the crisis developed, and the specific charge was rather diffuse. Since we were advisory to the National Institutes of Health, which is the major research arm of the U.S. Public Health Service. I interpreted it as mandating us to do what was needed to stay abreast of developments in the epidemic so that we could identify and highlight areas in need of more research attention. I assume that I was made chairman not only because of my FDA role, but also because I was a well-weathered survivor of the "influenza wars" in the wake of swine flu-and new national epidemic trouble was at hand.

The first couple of meetings of the NIH advisory committee were edifying and exploratory. Experts updated our group on all the major facets of the epidemic: general epidemiology. immunology, the status of transfusion-associated AIDS, the peculiarly high frequency of cytomegalovirus and Epstein-Barr virus infections in afflicted patients. the immunosuppression of hemophilia $A$. and even the progress of virology research in the laboratories of Drs. Montagnier and Gallo. While the status reports were interesting, nearly every one of them that had to do with human populations at risk ended abruptly with the reiterative comment that further progress was problematic or impossible because of unresolved ethical issues. Indeed matters of ethics surfaced so frequently that I proposed these issues be the agenda of our April 1984 meeting, commenting that, if research were being impeded by the need for an ultracentrifuge, we would all know what to do. Now that it was evident that it was being seriously stalled by a lack of an ethical consensus, it should also be clear what needed doing.

Thus was born what for a while was referred to as the "Osborn ethics meeting." (In fact, to this day some people think of the NIH committee as the "ethics committee.") Despite advance efforts to control the number of participants and to optimize for productive interaction between concerned parties, the meeting dawned on an assemblage of over 40 eager attendees crammed into an ill-shaped room in the Linden Hill Hotel in Bethesda near the National Institutes of Health. In addition to the committee members and the NIH staff, there were vociferous advocates of several divergent gay community factions, a number of agitated and alarmed blood bankers and hemophilia specialists, several persons well versed in ethical analysis and disputation, scientists from the FDA and the Centers for Disease Control, and several representatives of the Office of the Assistant Secretary for Health of the Department of Health and Human Services (HHS).

It is hard to reconstruct the arguments of the day, for so much has happened since then that a degree of cultural relativism has set in. It was exactly one month later, in May of 1984, that then HHS Secretary Margaret Heckler and Dr. Robert Gallo of the National Cancer Institute announced dramatically to the world that the new virus of AIDS had been found, that there would be a test for it that would allow us to cleanse the blood supply within six months; and that a vaccine could be expected in two years. 
(Parenthetically, the false hope inherent in that announcement was so tightly embraced by some members of the gay community that bathhouses which had stood virtually idle for many months were suddenly overflowing with four-hour waiting lines).

Since that announcement, if not before, we have been reaping the whirlwind. However, before that, at the meeting in April of 1984, the ethical issues swirled around confidentiality on the one hand and the patient/subject's right to know on the other. Astonishingly enough, by the end of the day a near-unanimous consensus had been reached on both points: that maintenance of confidentiality was crucial to progress in AIDS research, and that the days of medical paternalism were emphatically over - the patient had a right to know and, more importantly, the health care provider had no right to sequester personally pertinent information from those in his or her care. That "right to know" has laid a heavy challenge on health educators, for the issues are not easy; but these two cornerstones have survived during the ensuing two years and are the underpinnings of many present-day social policies involving not only the blood supply but also the public health management of the AIDS epidemic itself. One chief outcome of that meeting for me was the amazement I felt that such harmony of purpose could result from such a diversity of concerns; it prompts one to muse about the marvelous productivity that can arise from concerted human endeavor if and when the sensed risk is great enough.

In addressing the matter of AIDS and the social sciences, however, it is important to state my qualifications clearly; what I am is an AIDS generalist - with my own background as a virologist, immunologist, pediatrician, and amateur molecular biologist, I have tried to keep abreast of the furious pace of scientific progress. Also, my roles as state and federal advisor and as Dean of a school of public health have placed me in contexts where law, politics, economics, sociology, and ethics dominate or restrict choice of options and broaden the dialogue enormously. It became clear early that the languages of the natural sciences were nowhere near broad enough to encompass the range of problems posed by the peculiarities of the epidemic, and that we would all have to learn a much more universal language if we were to achieve both useful and socially acceptable measures of containment and control.

\section{THE NATURE OF THE NEW VIRUS AND ITS DISEASES}

First of all, we should start from a common conception of the problems we face. In brief, we are in the grips of a major epidemic caused by a virus that is entirely new to the human race. It may well have had its origin in Africa, probably in one or another species of monkeys which live in close proximity to humans and which serve as a food source for human populations in the area; and it made the species "cross-over" into humans less than 30 years ago, to the best of our discernment. ${ }^{2}$ Little is known of the mechanism of cross-over or of the interim status of the virus until 1977 when it was probably transported to the western hemisphere, first infecting Americans in 1978, with recognition of the new disease coming three years later.

Despite the fact that it is a "weakling virus" which is poorly transmissible by any means other than homosexual intercourse, more than a million Americans are now infected and nearly 25,000 have already developed the fully expressed disease we now call AIDS - an acronym for "acquired immunodeficiency syndrome." We do not know what fraction of the other infected persons will ultimately become ill, but it is not 
extremist to suggest that at least 270,000 Americans will probably sicken and die in the prime of their lives, even if we were able to prevent any further virus spread from this point forward.

We are not alone with this problem, for we have exported the virus widely since its introduction into the U.S. With the exception of parts of Africa and perhaps a few loci in the western hemisphere, much of the rest of the world owes its acquisition of the new virus to us, through sexual spread or through contaminated American blood products which were exported widely before and during the early years of the epidemic, prior to full recognition of the problem. In fact, a recent suggestion that the U.S. might screen immigrants and exclude those with antibodies to the virus of AIDS came perilously close to being a tasteless joke; for this is one facet of world commerce in the 1980's in which we are exporters, not inporters.

The result is that western Europe is now experiencing the same pace of increment in AIDS cases that we did, only two or three years behind us. Australia, Canada, Brazil, and other western hemispheric and some eastern European countries are experiencing the inexorable doubling in case numbers over each few months, and the sub. saharan African countries are recording a dramatic epidemic (although data from those areas are blotched and obscured by nationalism, contentiousness, and insensitivity). ${ }^{3}$

Large areas of the globe are populated by groups in which sex between males is a common phenomenon, but one which is entirely separated in their thinking from homosexuality as a way of life. Indeed bisexuality is a world-wide fact of life we must learn to deal with in the face of this epidemic, and it constitutes an unmeasured but probably immense component of the risk of further spread of the new virus. Certainly the careless collection and indiscriminate use of blood in third world medicine could fuel renewed conflagration and amplification of humanity's problems with this virus in the years to come.

All this would be terribly difficult and complicated to deal with even without further issues to snarl the situation. However, the problems posed by the sociology of the epidemic are nothing short of fiendish. The two largest high risk groups caught up in the terror are gay men and intravenous drug abusers, and both of these groups are subject to persecution and/or prosecution in most parts of the world. In the United States, the gay community had only just begun to try to express itself openly in the few years before the epidemic began, and the enlightenment of the 20th century seems not to have proceeded far enough to keep some from saying (much less feeling) that "it serves those people right!" In gatherings of such illiberal folk, miscited events at Sodom and Gomorrah have been revitalized (if not reread) in order to inject a degree of righteousness into discussions about how to dispense with, or incarcerate, the pitiful souls now dying slow deaths as a result of their virus infection.

Repressive herd reactions usually earn a backlash from their victims if they are strong enough to fight, and a few afflicted members of such high risk groups have indeed tried to strike back. The popular misconception that saliva could transmit the virus led one cornered felon with AIDS to turn on his captors and spit on them-in the feeble, vengeful but erroneous hope that he might truly be infectious-which act of defiance caused him to be booked on a charge of attempted murder.

Since more than $90 \%$ of the Americans caught up in the epidemic are either gay men or i. v. drug abusers, and another few percent are female prostitutes, the remaining groups at high risk have had to bear a double burden-they have acquired not only the virus and its disease but also the inferred stigmata. For instance, the few poor 
school boys currently being hounded out of school districts by community hysteria and judicial preemption are almost exclusively kids who had the misfortune to inherit such a large measure of the genetic defect for hemophilia $A$ that they require large amounts of factor VIII concentrate to stem their bleeding tendency and save their joints (and their lives) and thus were among the first harbingers of contamination of the blood supply.

These are little boys dying, and yet the media coverage has a slightly prurient tinge to it, as if their being infected with the virus of AIDS in some way conveyed a sort of seaminess to their doomed and lonely adolescent lives. I find interviews with such kids almost unwatchable, for the reporters struggle hard to avoid the obvious questions: "How does it feel to be treated like a leper?" "What did you think when half the kids stayed home from school just because you came to school?" "How does it feel to die slowly because of a virus you did nothing to acquire?" "To know you are dying?" (In my former incarnation as a pediatrician I occasionally had such talks with adolescent patients dying of rare malignancies, and believe me, dying children are insightful and astute beyond their years and beyond the credence of most adults - so these reporters' artful dodges are wasted on their prey, and I am sure the garish curiosity shines through.)

Adults with hemophilia A share the ignominy of these young boys, along with the spouses of bisexual men, the recipients of blood transfusions, and the Haitians whose involvement in the epidemic seems to have been an accident of place of birth. Perhaps the saddest of all are the parents of extremely premature infants whose life expectancy would have been nil without avant garde technology and the monitoring it entails in neonatal intensive care units. The monitoring of those tiny lives in the first few weeks requires such frequent blood tests that multiple replacement transfusions are needed to sustain progress, and so, in a technological vicious circle, a few of those "preemies" were saved in the early 1980's only to die from contaminated blood used earlier to help save them. After seeming to win such a long drawn-out war against the odds of prematurity, this loss in a later battle is devastating, and understandably the parental anguish is intensely poignant. The anger that often replaces that anguish propels grieving people to a lifestyle of courtrooms and lawyers and recriminations and dogged pursuit of whoever played such a divinely malicious trick on them.

Our habitual resort to lawsuits in times of trouble is a very new 20th century phenomenon, in which someone must be to blame for misfortune. Indeed, all this blaming is a striking hallmark of our new epidemic. As a society we seem to have had enough time to forget the paralytic polio that stalked summer swimming pools; the infantile tuberculosis which populated old graveyards with tiny headstones; the measles encephalitis which damaged irretrievably the intellect of thousands of children each year. We are so careless of our preventive heritage that we have deferred its maintenance, allowing litigation to threaten the very existence of superb vaccines which have helped to secure our unprecedented well being. True to our era, when trouble arises one-in-amillion times in the vaccine world, we blame and sue.

Fairly recently I lectured to a graduate class at my school about the virologic data which indicated the probable origin of the AIDS virus in Africa. One student interrupted me rather angrily, saying that she had worked in the Peace Corps in the areas of which I spoke and that she "didn't think it was fair to blame the Africans for what had happened." I was so startled by her comment that it took me a minute to understand the concern: then I asked "To whom do you ascribe blame for the Colombian 
volcano? or the Mexican earthquake?" I fear we have come to think of ourselves as living in a controllable, plexiglass world like the bubble boy, and we have lost the sense of community with nature which is, nonetheless, inescapable.

In summary, then, we are in the throes of a late-20th-century epidemic, and our lack of recent memory and a quixotic but pervasive atavism are distorting our responses at a time when we need all the sophisticated community synergism and creative energy amassed throughout human history to cope with the mounting problems that the extraordinary epidemic presents.

I should describe briefly the virus and its diseases, although much of this litany has appeared many times in the popular press. The disease AIDS is caused by a new virus, as I have indicated, and it is only one disease syndrome at the tip of an iceberg of virus infection: that is, of the great number of virus-infected individuals, the majority have no disease. That is not at all unusual in microbiology and infectious disease: for instance in the days before polio vaccines, for every 100 infected persons only one would develop recognizable paralytic disease, a few might have fever and a bad headache, but the rest would have no recognizable disease at all even though one could tell later from their antibody responses that they had indeed been infected with poliovirus.

Similarly, with the virus of AIDS, even in the high risk groups, the majority of infected people are entirely asymptomatic, some have persistently enlarged lymph nodes, and only a fraction have the more serious diseases called the AIDS-related complex or AIDS itself. The virus is too new for us to state with any certainty what fraction will ultimately develop AIDS, but there is reason to think that many factors besides the virus infection itself can influence that probability-including many facets of behavior which are potentially susceptible to person decision making and modification of health behavior. Thus the need to understand and communicate matters of health becomes quite urgent.

There is one quality of the virus infection that is not common to most human pathogens, and that is its durability. The virus of AIDS is a member of the group of viruses called retroviruses which have a unique way of infecting their hosts. While many retroviruses are known to infect domestic and other animal species, no common human pathogens were previously known from this group. By virtue of the means whereby these viruses initiate infection (well before they provoke an antibody response) their nucleic acid is woven intimately into the DNA of human cells like a set of new, unwanted genes. We do not know how to excise such invader genes, and the cells harboring them may be too precious to eradicate in an all-out effort to rid the host of virus. Thus we are presented from the very start with a situation in which. once the infection is initiated, total cure is for the moment unimaginable and therapeutic intervention is a holding action at best, aimed at preventing further virus multiplication and damage. Once these facts are fully absorbed, the urgancy of prevention and avoidance of virus infection becomes obvious.

\section{AVOIDANCE AS A SUCCESSFUL PERSONAL STRATEGY}

Mercifully, the virus of AIDS is a weakling when it comes to transmission. Only homosexual intercourse seems to transmit the virus with any efficiency, and anal receptive homosexual intercourse is very significantly more efficient than are other modes 
of transmission. Clearly, blood can transmit virus, but probably only in unusual circumstances or in large volume transfusions (and the latter source has been virtually eliminated in the U.S. with the advent of blood and plasma screening for virus antibodies). Infants can and do acquire AIDS from infected mothers, most of whom have been prostitutes, intravenous drug abusers or both-but it is not known whether the infantile infection is acquired transplacentally, through blood contamination at birth, or via breast milk. That nearly completes the list of modes of transmission. Females can transmit the virus to males through heterosexual intercourse (and clearly that happens in some instances), but the pattern of infection and spread (at least in the United States) suggests that heterosexual spread is vastly less efficient than homosexual. $^{4}$

The really good news, then, is that true avoidance of the virus is possible. That has not been true of any epidemic in recent times-probably not since leprosy. While the virus can be shown to be present on occasion in saliva and tears, there is no suggestion that it can be spread by those means. Many worried people have brought up the fear of mosquito spread, but epidemiologic patterns simply do not bear that possibility. In fact, even in the closest nonsexual contacts you can imagine, the virus does not spread - much less the disease. In close families with a member suffering at home from AIDS, no nonsexual household contacts have even acquired the virus. ${ }^{5}$ In over 600 health care workers contaminated directly by material from AIDS patients, none has become ill, and only three have acquired antibodies, of whom two have other possible sources of virus complicating the picture. ${ }^{6}$ By contrast, hepatitis B would have caused infection in at least 200 of such health-care workers.

\section{NEUROLOGIC DISEASE AND AIDS}

Now that we know about the virus and its probable origin and epidemiology, where does that leave us? The volume of research effort to understand the disease AIDS has left us with an increasing comprehension of the new virus' interaction with humans, once infection is established; and while we have already briefly reviewed the fact that a lack of disease is the usual outcome, it is worth going a but further to understand some of our worries for the future.

While the first descriptions of AIDS focussed on the unusual infections and tumors to which their destroyed immune systems left the sufferers prone, more recent clinical analyses have raised a new and alarming concern: there is growing reason to suspect that a large fraction of AIDS patients have the virus of AIDS in their central nervous systems. At first that fact was missed; many patients had depression as a major part of their initial illness, but since the diagnosis was recognized from the beginning to carry a very dire prognosis, depression seemed to be a natural response. Quite recently, definitive case descriptions have established that the initial manifestation of AIDS can take the form of an acute encephalitis, ${ }^{7}$ and the investigators have now sought for and found the virus of AIDS in the cerebrospinal fluid which bathes the brain and spinal cord, even when no signs of neurologic disease are present at the time of search. $^{8}$

These disturbing findings raise one of two major possibilities: either the initial invasion of the virus includes entry into the central nervous system, or reactivation of the virus at the time of onset of the disease often or always includes central nervous 
system invasion. The former possibility is truly a disastrous one, for the so-called blood-brain barrier provides a formidable obstacle to many pharmaceutical agents and greatly complicates efforts at chemical intervention or control. The latter possibilitythat central nervous system invasion is secondary-prompts a renewed intensity of research into so-called "co-factors," i.e., factors other than the virus of AIDS which may reactivate or prod the virus genes from an asymptomatic or unexpressed state into a productive and lethal interaction with the host's immune system.

\section{CO-FACTORS INVOLVED IN PROGRESSION FROM ASYMPTOMATIC INFECTION TO DISEASE}

The idea of co-factors is not new; many such factors were under consideration as contributors to the AIDS epidemic before the new virus was identified, and the fact that only a small percentage of individuals who are infected have gotten sick thus far should spur us to look for other elements which could influence their fate. In the high risk communities, such co-factor possibilities are not hard to find; by virtue of the fact that immune stimulation is very likely to lead to reactivation of the AIDS virus, the multiple infections of the gay community are clearly suspect. Furthermore, some of the infections suffered by gay men (such as cytomegalovirus and Epstein-Barr virus infections) are themselves immunosuppressive, suggesting that a synergistic interaction might be at play.

The threat posed by intense immune stimulation also underlays, in part, the decision of the military to bar antibody-positive individuals from enlisting, since a barrage of live-virus vaccines is one of the first experiences a new recruit has in military service. There may have been other considerations involved in that decision, but at least that one has considerable validity with respect to the welfare of the potential inductee or recruit.

Immune stimulation from so-called antigenic overload has been invoked as a possible explanation for the occurrence of AIDS in hemophiliacs - the disease has focussed largely on severely afflicted persons whose extreme lack of clotting factor has led to the need for multiple infusions of Factor VIII concentrate representing donations from literally thousands of persons, each with their own distinctive histocompatibility and other antigens. Indeed it can be shown that such severe hemophiliacs are somewhat immunosuppressed even if they are not infected, and so synergism is again a possibility to explain the advent of AIDS disease.

Even the transfusion recipients who developed AIDS were not, as a rule, ordinary. The average transfusion recipient receives at most two units during time of need, whereas transfusion recipients who developed AIDS had averaged more than 14 units in the first relatively large group studied. ${ }^{9}$ While that could simply represent the increased likelihood of exposure with increasing units, it could also represent antigenic stimulation (from the multiple transfusions) acting as a co-factor.

One of the most interesting co-factors currently under discussion and one that could be of major importance for the gay community to understand is the possibility that repeated infection with the virus of AIDS itself may play a crucial role in determining the outcome of infection. There is already a good indication that superinfection can occur; that is, someone infected with one variant of the AIDS virus can acquire another variant as well. ${ }^{10}$ The virus has the disturbing property of being able 
to change its genetic makeup and therefore its antigenic "spots," and this, in turn, allows for the possibility of multiple infections. If such phenomena are important in tipping the balance, it will be crucial to learn so quickly, in order to guide members of high risk groups away from a nihilistic strategy of consorting among antibody-positive cohorts.

A co-factor of terrible significance about which we already know quite a bit is pregnancy. It has been shown that mothers who deliver one AIDS baby and are thus recognized to be asymptomatically infected will not only infect a second offspring most of the time but will themselves often sicken and die of fulminant AIDS! ${ }^{11}$ Again, this is not necessarily surprising, since pregnancy is a condition in which immunosuppression is known to occur, but it is a dramatic fact and underlies the rather cold-sounding recommendation of the U.S. Public Health Service to the effect that seropositive mothers should avoid pregnancy.

These examples of co-factors are only a partial list. We know that certain "recreational drugs" used in the gay community have immunosuppressive properties; and it may be that drugs which are commonly abused intravenously also have their own intrinsic immunosuppressive effect. On a more difficult level to prove, there are reiterative reports in the literature that emotional perturbation can suppress immune responses, particularly including acute bereavement, which is most germane to the present epidemic. Thus we need to learn what kinds of factors play an additive or synergistic role which might prod the virus of AIDS from latent quiescence into productive expression and immune cell death in the host.

\section{THE VIRUS OF AIDS VS. CIVIL LIBERTIES: BARRIERS TO EFFECTIVE COMMUNICATION}

The foregoing discussion has revolved around matters of biomedical science, and there the certainties are growing, thanks to much progress in recent decades in the areas of immunology, virology, and molecular biology. However, as noted at the outset, the AIDS epidemic has tapped every facet of society and every realm of human intellectual endeavor, and some aspects of that broad impact should also be reviewed.

Above all, it has highlighted an obvious but often-ignored fact: individual liberty always exists in precarious balance with public interest. Someone recently commented, as if it were a new insight, that "this epidemic has really brought out a tension between civil liberties and public health." I suspect that this tension is always there, and that it is (or should be) a hallmark of our democratic tradition that we go to extraordinary lengths to optimize both. The perpetuation of sodomy laws, the cries for prostitutes to stop doing what they are doing (as if they knew another way to support themselves and their often-unwanted children), and the moves toward quarantine laws are all throwbacks to a simpler era-simpler because the power of the democratic tradition to solve these problems to the benefit of all was appreciated less then than it should be now. I recently received from a colleague a xerox copy of the narrative report from the 1939 medical literature submitted by the physician/public health officer who spent most of his career tracking, incarcerating, and studying Typhoid Mary. ${ }^{12}$ It makes fascinating reading, for greater leeway was allowed by the journals in those days for self-expression, and the author's sense of triumph at having cornered and caged a public health menace is not tempered appreciably by a sense of the altered 
lifestyle to which he had rather single-handedly condemned Mary. By the same token, none but righteous tones were tried in an effort to teach Mary to wash her hands or to learn a career other than food preparation. The triumph of epidemiologic involvement of the 1930s reads like Dickens to the 1980 s public health professional or physician. We really ought to have come farther along the road of civilization than that, and we ought not to 'cop out' now with the simple declaration that, since there is a tension between civil liberties and public health, the latter should simplistically prevail.

In case love of the Constitution and Bill of Rights is insufficient motivation to try harder, it is also worth emphasizing the invasion of privacy, loss of confidentiality, and coercive approaches proposed for testing and disclosure of infected individuals all threaten to turn this into an undergound epidemic. Even in the transition from research initiatives which in the early days guaranteed confidentiality to participants) to clinical studies in which confidentiality cannot be so firmly assured, we have witnessed the attrition of high risk participants whose full identification would put them at risk of job, family, insurance, and even domicile. It is a marvel that we can get such forthcoming medical histories at all, when to confess membership in a high risk group is to risk charges of felony in so many cases! If confidence in their ability to retain privacy is further eroded, imagine how easy it will be to get such high risk group members to line up for vaccine efficacy studies should a vaccine-candidate be created by science. That is one of the many reasons why I contend that we should not be counting on a vaccine as a solution to our problen; it represents a very false hope for the near future which could seriously distract us from our public policy issues and attention.

\section{THE IMPORTANCE OF LANGUAGE IN COMMUNICATION}

Turning from civil liberties to other aspects of public policy, let me pause for a minute on the issue of prudery in high places. It is clear that we have at hand sufficient information to know that prevention is not only the only effective strategy for the individual presently faced with this epidemic, but also that it is indeed a most effective strategy. From our present knowledge, firmly grounded on epidemiologic and virologic bases, guidelines have been developed to counsel high risk groups about safe and unsafe practices. In particular, the gay community has been participant in developing the so-called "safe sex" guidelines which basically involve the avoidance of certain homosexual practices and the prevention of exchange of body fluids. The need to convey this information is important not only in preventing further de novo infection in the gay community, but also in limiting the likelihood of reinfection should repeated exposure to the virus of AIDS prove to be of pathogenetic significance.

Initial attempts to develop such guidelines, in response to federal requests for proposals, were at first accepted but then turned back on the grounds that the government could not "be perceived to condone" such behavior and therefore could not sponsor written materials about such matters. In a related event, a group in Los Angeles tried to walk the narrow line of acceptability by wording health education brochures about "safe sex" in what they hoped would be a governmentally permissible fashion, with the result that their intended readers found the brochures totally unintelligible. I think the message is obvious: if you intend to talk to someone and communicate meaningfully, it is best to do so in their language, not yours. If health 
education about health behavior ir our sole weapon against this dread new virus, it may be that we cannot afford government prudery at such a crucial time.

\section{HEALTH EDUCATION AS THE WINNING (AND ONLY) STRATEGY}

In summary, then, the good news is that we know quite a bit about the new virus and the epidemic it has caused; we know that co-factors may play a very large role in determining whether disease results from virus infection; and there is no shortage of co-factors to be explored as possible contributors to disease onset and progression in the pathogenesis of AIDS. The urgency of the need to assess these co-factors is manifest in the fact that an estimated 1-2 million asymptomatic individuals now live under the shadow of a lethal disease, and the likelihood of that occurring may not only be influenced but actually determined by behavior and choices under their control. Many of these submit to health education strategies in a manner quite analogous to counselling concerning juvenile-onset diabetes. In fact, I find the diabetes analogy quite useful in thinking about this problem. In that instance, the new juvenile diabetic has discovered (with much initial shock) that his/her islet cells are not to be relied upon and that life style changes will be necessary, with which changes he/she can anticipate good health and a relatively normal longevity. In the instance of infection with the virus of AIDS, I hope it may turn out to be that one need only substitute the term "T-cells" for "islet cells" and the rest of the message may be similar. If we can learn enough about determinants of progression in the context of virus infection, we may be able through health education to define life styles which facilitate continued good health and normal longevity despite the lurking threat of viral activation.

This message seems up-beat until the reader says "Wait a minute: you are pinning your hopes on effective health education and counselling, which are notoriously puny weapons in the face of even less dramatic forces than sexual urges and drug addiction." That is true, but I have some pretty fearful forces on my side as well: not only the fear of death but, for some perhaps more awesome, the fear of progressive, degenerative neurologic disease en route to one's demise. As smokers illustrate so clearly, people are remarkably willing to play a kind of roulette with lung cancer or even myocardial infarction. I suspect that the risk taking would be perceived quite differently if they had a clear vision of incontinence, incoherence, and neurologic deterioration in the odds picture, as they seem to be in this circumstance.

My dreary basis for optimism has some support, in fact-one can indeed influence even sexual behavior if the warnings are sufficiently frightening. Rectal gonorrhea is accepted as a useful indicator of gay male "unsafe" sexual activity, and the data on decline of rectal gonorrhea among gay men in the hardest hit cities of this country are nothing short of startling as testimony to genuine fear. I am told that most experts would judge a sustained $5 \%$ change in a given adverse behavior to be a truly impressive outcome of health education and counselling, and yet there has been a dramatic decrease in rectal gonorrhea sustained over nearly the past two years in both New York and San Francisco. Similarly, the self-reporting of numbers of sexual partners among gay men (while fraught with some hazard) supports the notion that AIDS has had a remarkable chilling effect on what had appeared to be an out-of-control, hot life style. ${ }^{13}$ Certainly bi-sexual persons have strong cause for reassessment of their catho- 
licity of taste; and, to the extent that female prostitutes constitute some degree of threat (they are certainly infected with a fair frequency) the individual choice to patronize them takes on a deadly tinge which may be much more effective as a deterrent than were the paler fears of gonorrhea, syphilis, and even herpes.

All of this leads to the conclusion that it behooves us to swiftly resolve the nonhealth-related problems which make it difficult or unwise to advocate widespread screening for antibody to the virus of AIDS at this time. The reasons not to screen lie in the realm of civil liberties and personal realities such as loss of job, insurance, home, and friends. Yet either the knowledge that one is uninfected or the awareness that one is asymptomatically infected has its own kind of important impact on individual and public health. The urgency of co-factor assessment lies in our wish to counsel the infected group, who must be aware of their infection before they can take matters seriously. The gay community, in an effort to be responsible while keeping a weather eye to the law, has urged high risk group members to assume that they are infected and then behave accordingly. I believe that there is a vastly different impact on behavior if you read a pamphlet about smoking and lung cancer, compared with receiving a lab report telling you that you have atypical cells in your bronchial washings.

On the other side of the question, the fear of infection when none is present is presumably contributing to enormous anxiety in countless individuals whose transient deviation from standard behavior has put them at perceived risk, and the reassurance of a negative test would have a major positive health impact on them as well as opening the way for effective avoidance counselling. The barriers to screening are very real, but it must be emphasized that they lie in the realm of civil liberties, not in the realm of biomedical science. Our need to resolve this and to speak plainly - in the language of our intended listeners - in health counseling, are matters at least as urgent as cofactors in facilitating progress in this awful epidemic.

\section{References}

1. For a review of the underlying science of AIDS, see: Osborn JE: The AIDS epidernic: an overview of the science. Issues in Science and Technology II: 40-55, 1986.

2. Kanki PJ, Alroy J, Essex M: Isolation of T-lymphotropic retrovirus related to HTLV-III/LAV from wild-caught African green monkeys. Science 230: 951-954, 1985.

3. Biggar RJ: The AIDS problem in Africa. Lancet i: 79-83, 1986.

4. Redfield RR, Markham PD, Salahuddin SZ, Wright DC, Sarngadharan MG, Gallo, RC: Heterosexually acquired HTLV-III/LAV disease (AIDS-related complex and AIDS). Epidemiologic evidence for female-to-male transmission, JAMA 254: 2094, 1985.

5. Friedland GH, Saltzman BR, Rogers MF, Kahl PA, Lesser ML, Mayers MM, Klein RS: Lack of transmission of HTLV-III/LAV infection to household contacts of patients with AIDS or AIDS-related complex with oral candidiasis. New Eng J Med 314: 344-349, 1986.

6. Weiss SH, Saxinger WC, Rechtman D, Grieco MH, Nadler J, Holman, S, Ginzburg HM, Groopman JE, Goedert JJ, Markham PD, Gallo RC, Blattner WA, Landesman S: HTLV-III infection among health care workers: association with needle-stick injuries. JAMA 254: 2089-2093, 1985 .

7. Carne CA, Smith A, Elkington SG, Preston, FD, Tedder RS, Sutherland S, Daly HM, Craske J: Acute encephalopathy coincident with seroconversion for anti-HTLV-III. Lancet ii: 12061208,1985 .

8. Ho DD, Rota TR, Schooley RT, Kaplan JC, Allan JD, Groopman JE, Resnick L, Felsenstein D, Andrews CA, Mirsch MS: Isolation of HTLV-III from cerebrospinal fluid and neural tissues of patients with neurologic syndromes related to the acquired immunodeficiency syndrome. New Eng J Med 313: 1493-1497, 1985. 
9. Curran JW, Lawrence DN, Jaffe H, Kaplan JE, Zyla LD, Chamberland M, Weinstein R, Lui KJ, Schonberger LB, Spira TJ, Alexander WJ, Swingee G, Ammann A, Solomon S, Auerbach D, Mildvan D, Stoneburner R, Jason JM, Haverkos HW, Evatt BL: Acquired immunodeficiency syndrome (AIDS) associated with transfusions. New Eng J. Med 310: 69-75, 1984.

10. Wong-Staal F, Shaw GM, Hahn BH, Salahuddin SZ, Popovic M, Markham P, Redfield R, Gallo RC: Genomic diversity of human T-lymphotropic virus type III (HTLV-III). Science 229: $759-762,1985$.

11. Scott GF: Reported at the International Conference on Acquired Immunodeficiency Syndrome (AIDS), Atlanta, Georgia, April 1985.

12. Soper GA: The curious career of Typhoid Mary, Bulletin of the New York Academy of Medicine 15: 698-713, 1939.

13. McKusick L, Wiley JA, Coates TJ, Stall R, Saika G, Morin S, Charles K, Horstman W, Conant MA: Reported changes in the sexual behavior of men at risk for AIDS, San Francisco, 198284 - the AIDS behavioral research project. Public Health Reports 100: 622-628, 1985. 